\title{
KINEMATICS AND DYNAMICS OF TWO STAGE CYCLOIDAL GEARBOX
}

This article presents results of the numerical analysis of cycloidal gearbox, which were obtained in MSC Adams engineering software. Multibody geometry for dynamical analysis was designed in Autodesk Inventor Professional 2017 and imported in MSC Adams. The results of analysis are forces acting on the internal and external sleeves, position, velocity and acceleration of the selected points on the cycloidal gearbox's moving components. Indirect result is time course of the torque at output shaft which was calculated on the basis of forces acting on the internal sleeves, which are parts of the equilibrium mechanism and displacements of these sleeves. Knowledge about cycloidal gearbox's loading conditions is important in its design process. Main advantage of a cycloidal gearbox is distribution of the forces on multiple external sleeves, while in majority of other gears only one tooth is in contact at a time.

\section{INTRODUCTION}

Simulation of cycloidal gearbox can be done in software designed for multibody dynamics. Gears have cycloidal shape and it leads to many complications in design of a simulation model. Mechanism of cycloidal gearbox should be assembled from many parts and it leads to many modeling difficulties. In Autodesk Inventor Professional 2017 software, constraints were applied on the component bodies' axes and collision detection tool was used. Idea of constraints is helpful in geometry design of eccentric shafts, which have constraint applied on axes and radial displacement of the pins. In geometrical model, interference of the bodies can lead to numerical problems if an analysis allows contact of the bodies. Collision detection tool in Autodesk Inventor was used to set up a cycloidal gearbox mechanism in starting position without interference of component bodies.

Geometry designed in Autodesk Inventor was imported in MSC Adams engineering software, which is designed for multibody dynamics. Two models based on the imported geometry were designed in MSC Adams. The first model contains only rigid bodies and the second model contains two rigid cycloidal gears and flexible bodies: internal and external sleeves, input and output shafts. Connections between bodies were set up by the application of bearings. Each bearing is a radial-thrust connection which follows its application point on a given component body and rotates with friction during motion of the cycloidal gearbox mechanism.

Geometry prepared in Autodesk Inventor is shown in Figure 1. It consists of the following bodies: input shaft, output shaft, 8 internal sleeves, 16 external sleeves and 2 cycloidal gears. Model which was prepared in MSC Adams (which is shown in Figure 2) consists of the same bodies, but there are also two bearings on the each external sleeve, two bearings on each shaft and one bearing in each cycloidal gear. Contacts was set up between external sleeves and each cycloidal gear and between internal sleeves and each cycloidal gear. Analysis parameters are shown in Table 1 and 2.

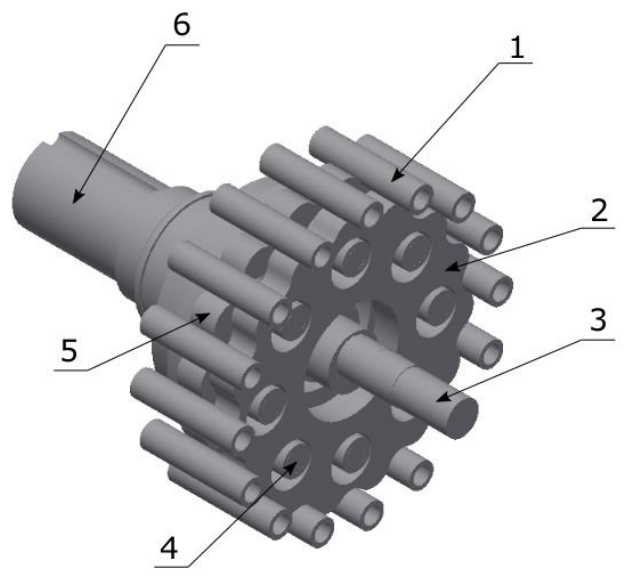

Fig. 1. Geometry of the cycloidal gearbox prepared in Autodesk Inventor: external sleeve (1), external cycloidal gear (2), input shaft (3), internal sleeve (4), internal cycloidal gear (5), output shaft (6)

Tab. 1. Analysis parameters: torque and velocity

\begin{tabular}{|c|c|}
\hline Parameter & Value \\
\hline Input torque & $1.55 \mathrm{Nm}$ \\
\hline Output torque & $22.26 \mathrm{Nm}$ \\
\hline Angular velocity of input shaft & $500 \mathrm{RPM}$ \\
\hline Analysis time & $0.36 \mathrm{~s}$ \\
\hline
\end{tabular}

Tab. 2. Analysis parameters: masses of the component bodies

\begin{tabular}{|c|c|}
\hline Part name & Mass [kg] \\
\hline Internal cycloidal gear & 0.599 \\
\hline External cycloidal gear & 0.599 \\
\hline Input shaft & 0.232 \\
\hline Output shaft & 1.815 \\
\hline Internal sleeve (excluding the pin) & 0.0235 \\
\hline External sleeve & 0.0245 \\
\hline
\end{tabular}




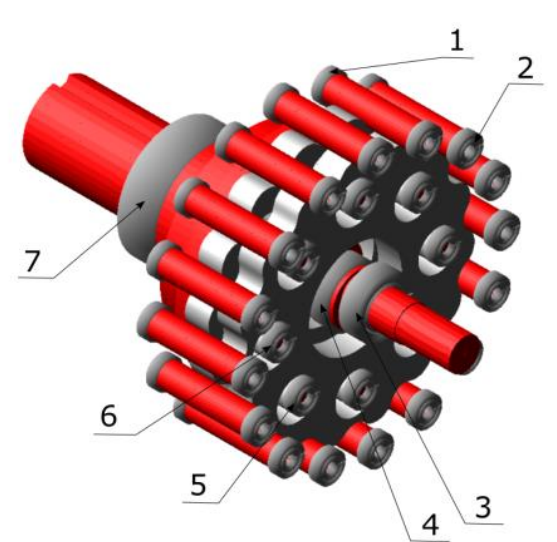

Fig. 2. Finite element model in MSC Adams (the second model): bearings on external sleeves $(1,2)$, bearing on input shaft (3), bearing on eccentric pin of the input shaft, where the housing is external cycloidal gear (4), bearing on internal sleeves $(5,6)$, bearing on output shaft (7). Red bodies are flexible (consist of tetrahedral finite elements), gray bodies are rigid

\section{KINEMATICS OF CYCLOIDAL GEARBOX}

Kinematic quantities was determined in the first model. Points "A" and "B", for which kinematic quantities were calculated are shown in Figure 3. These points lie on the internal cycloidal gear.

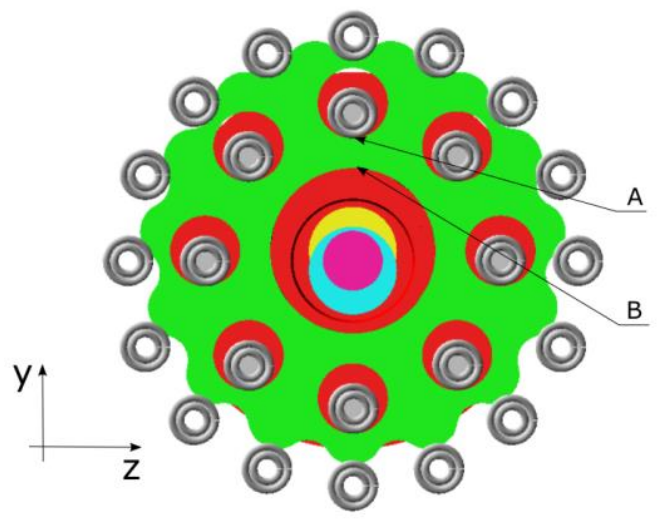

Fig. 3. Points "A" and "B" on the internal cycloidal gear, for which position, velocity and acceleration time courses were determined

Time courses of the points' "A" and "B" position components during 18 rotations of input shaft are shown in Figure 4 and 5 . In Figure 6 and 7 velocities of these points are shown and in Figure 8 and 9 acceleration of the point " $A$ " is presented.

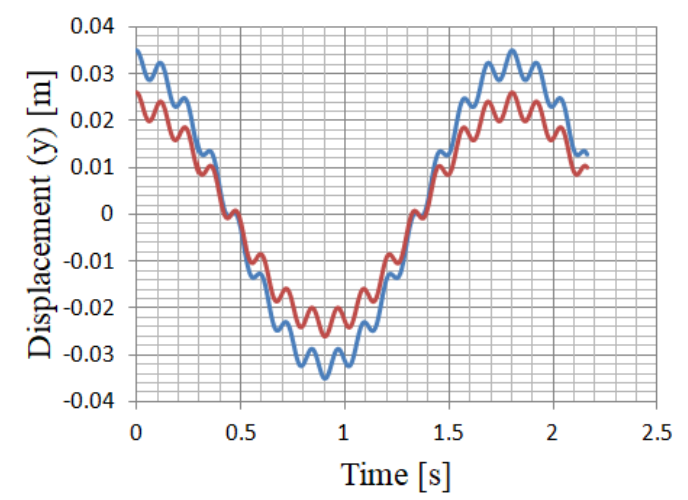

Fig. 4. Y-components of the points' " $A$ " and " $B$ " displacements (Fig. 3)

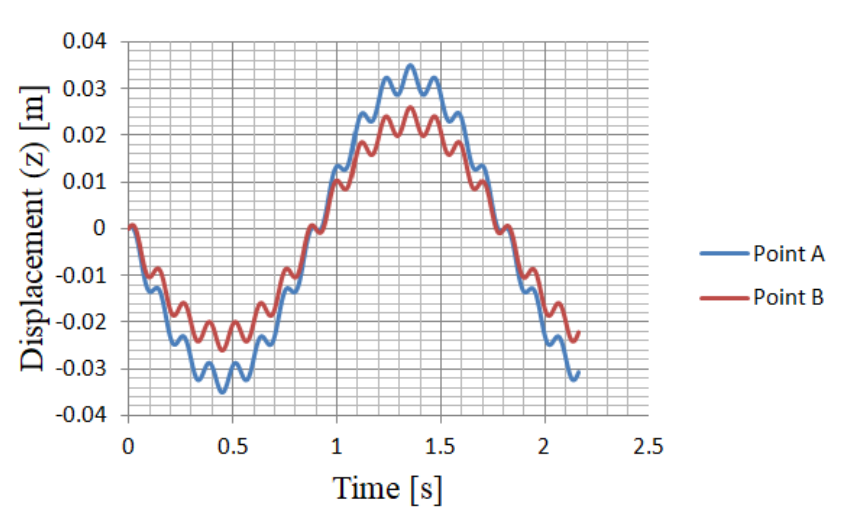

Fig. 5. Z-components of the points' " $A$ " and " $B$ " displacements (Fig. 3)

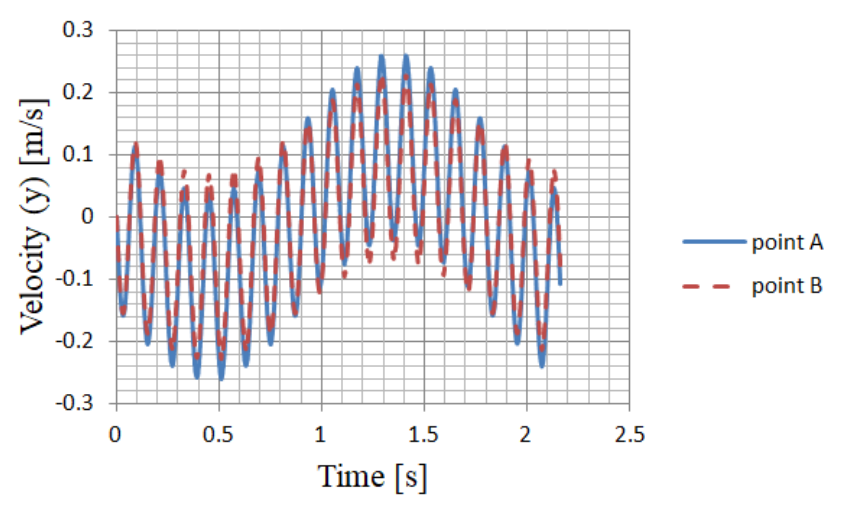

Fig. 6. Y-components of the points' " $A$ " and " $B$ " velocities (Fig. 3)

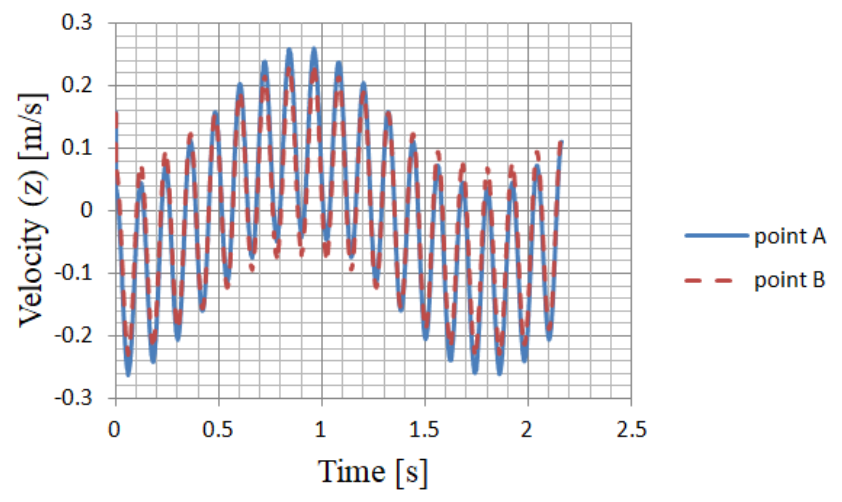

Fig. 7. Z-components of the points' "A" and "B" velocities (Fig. 3)

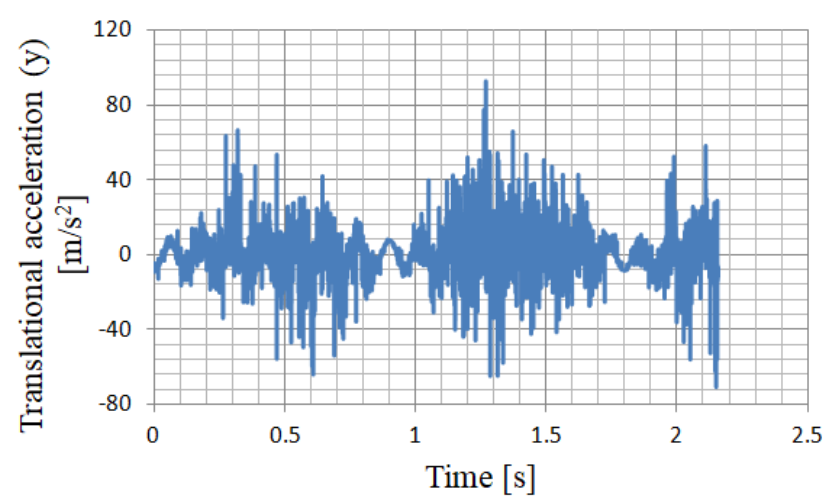

Fig. 8. Y-component of the point's "A" translational acceleration (Fig. 3) 


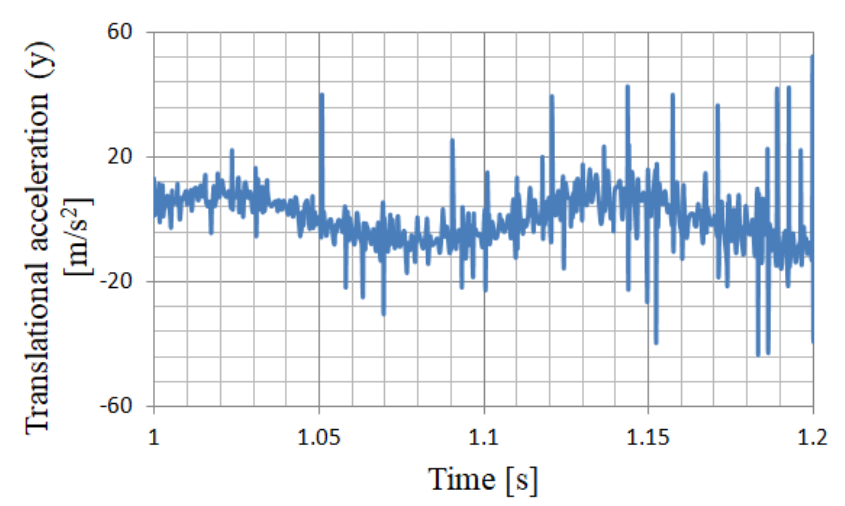

Fig. 9. Y-component of the point's " $A$ " translational acceleration in a shorter time span

\section{FORCES ACTING ON EXTERNAL SLEEVES}

The advantage of a cycloidal gearbox is that many lobes can work at the same time. Numerical simulation showed forces acting on the external and internal sleeves (Figure 10 and 11 respectively). Important part of cycloidal gearboxes' optimal design $[1,3,4,5]$ is analysis of the forces acting on sleeves. Information obtained during analysis can be used in further fatigue-life analysis of the sleeves in which significant deformations occur.

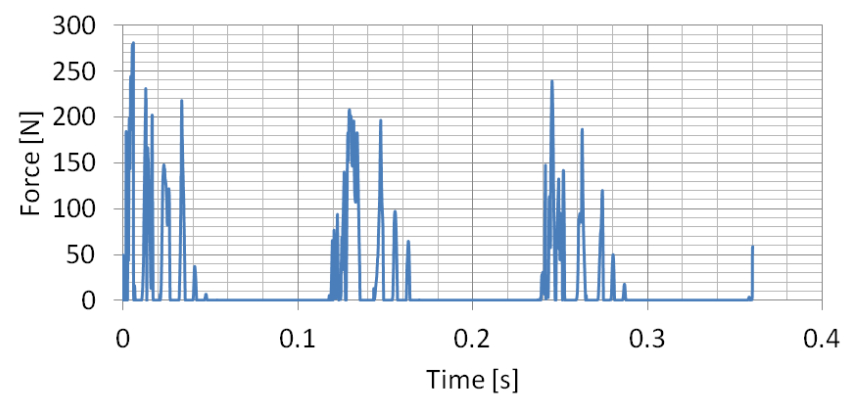

Fig. 10. Force acting on the one of the external sleeves during three revolutions of the input shaft

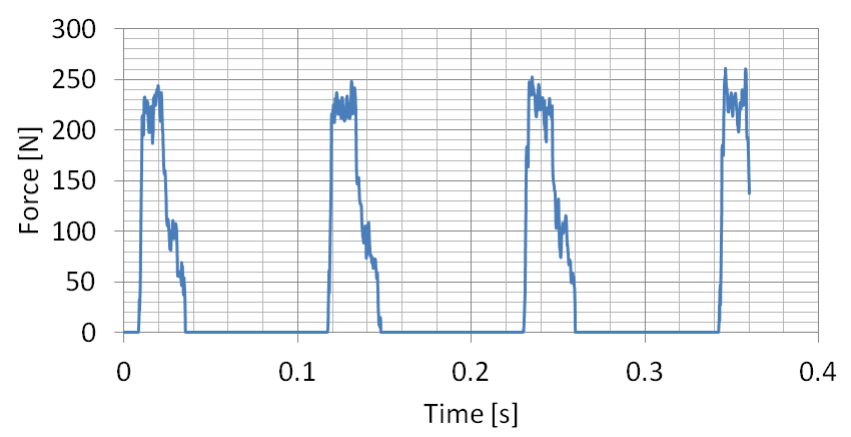

Fig. 11. Force acting on the one of the internal sleeves during three revolutions of the input shaft

From Equation (1) and (2) forces acting on the external sleeves were calculated. These results are shown in Table 3.

$$
\begin{gathered}
P_{\max }=\frac{4 \cdot M_{C}}{r_{A} \cdot z_{b}}, \\
P_{i}=P_{\max } \cdot \frac{l_{i}}{l_{\max }} .
\end{gathered}
$$

where: $P_{\max }$ - maximum force acting on the external sleeve, $\mathrm{Mc}_{\mathrm{C}}$ - output torque from the one cycloidal gear, $\mathrm{r}_{\mathrm{A}}$ - radius of the circle that makes the point of concentration of force lines in the meshing of the cycloidal gear, $z_{b}$ - number of external sleeves, $\mathrm{l}_{\mathrm{i}}$ - force arm from the center of the mentioned circle to the given force line which is normal to the force line, I $\max$ - maximum force arm length. Exemplary arms: NR and SN are shown in Figure 12.

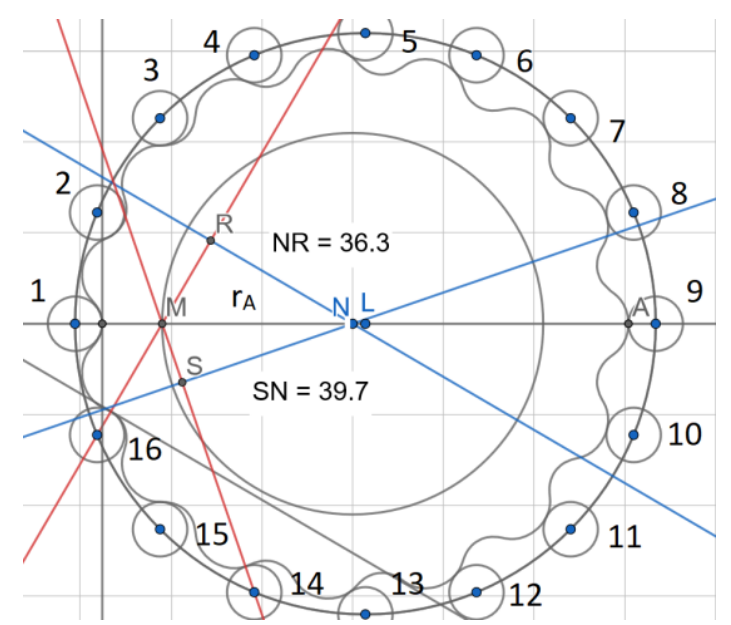

Fig. 12. Exemplary force arms NR and $S N$ (blue sections), the $r_{A}$ $(M N)$ is the radius of the circle that makes the point of intersection of the force lines (red lines) during motion of the cycloidal gear. $L$ is the center of rotation of the input shaft and $N$ is the eccentric point

Tab. 3. Forces acting on the external sleeves calculated from equation 1 and 2

\begin{tabular}{|c|c|c|}
\hline Sleeve number (Fig. 12) & Force arm length [mm] & Force [N] \\
\hline 1 & 42 & 66 \\
\hline 2 & 36.3 & 57 \\
\hline 3 & 42 & 66 \\
\hline 4 & 39.7 & 63 \\
\hline 5 & 34.4 & 54 \\
\hline 6 & 27.3 & 43 \\
\hline 7 & 18.9 & 30 \\
\hline 8 & 9.6 & 15 \\
\hline 9 & 60.8 & 96 \\
\hline 10 & 9.6 & 15 \\
\hline 11 & 18.9 & 30 \\
\hline 12 & 27.3 & 43 \\
\hline 13 & 34.4 & 54 \\
\hline 14 & 39.7 & 63 \\
\hline 15 & 42 & 66 \\
\hline 16 & 36.3 & 57 \\
\hline
\end{tabular}

\section{TORQUE AT OUTPUT SHAFT}

Torque at the output shaft given in Figure 13 and 14 was calculated from the Equation (3) and (4) on the basis of forces acting on the internal sleeves (Figure 11).

$$
\begin{gathered}
M_{n}=\vec{r} \times \vec{F}, \\
M=\sum_{n=1}^{8} M_{n}
\end{gathered}
$$

where $M$ is the moment at the output shaft, $M_{n}$ is the moment from $n$-th internal sleeve, $\vec{r}$ - is the position vector of the given internal sleeve's center of mass, $\vec{F}$ - is the resulting force vector acting on the internal sleeve.

Numerical analysis showed the torque fluctuation at output shaft (Figure 13 and 14). Peak-to-peak value of the torque at output shaft calculated in the second model is $4.329 \mathrm{Nm}$ and in the first 


\section{Eksploatacja i testy}

model is $3.316 \mathrm{Nm}$. Average output torque is $22.305 \mathrm{Nm}$ in the second model and $22.378 \mathrm{Nm}$ in the first model. Measurements $[3,5]$ showed fluctuation of the input torque. In MSC Adams the spline, which represents input torque fluctuations was defined and applied as an input torque in the cycloidal gearbox's numerical model. These input torque fluctuations are shown in Figure 15. In Figure 16 torques at output shaft with fluctuations of the input torque and with constant input torque are shown.

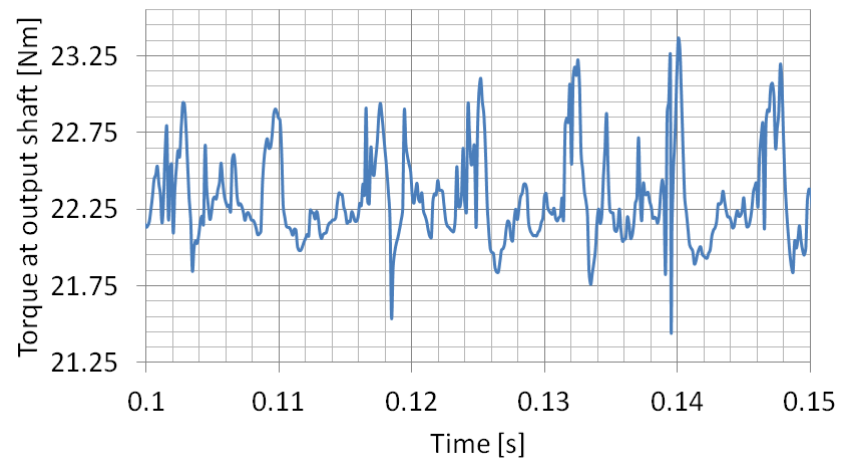

Fig. 13. Torque at output shaft calculated in the first model on the basis of forces acting on the internal sleeves

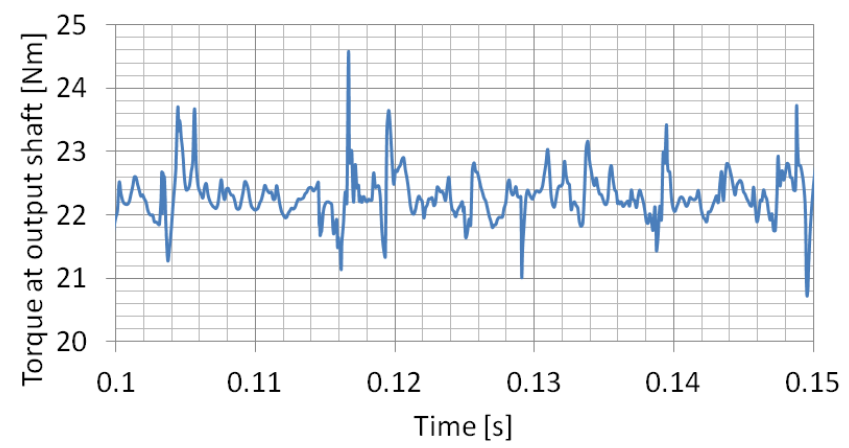

Fig. 14. Torque at output shaft calculated in the second model on the basis of forces acting on the internal sleeves

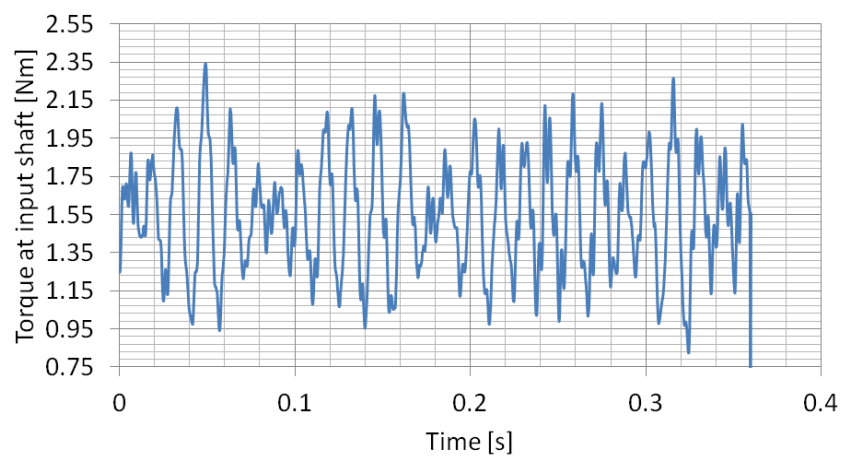

Fig. 15. Fluctuation of the torque at input shaft, measured in experimental stand $[3,5]$

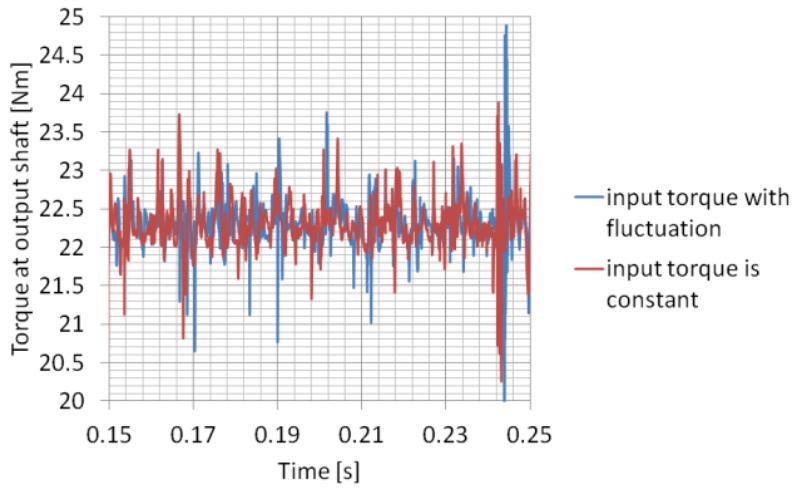

Fig. 16. Torque at the output shaft when input torque is with fluctuation (Figure 15) - blue line and when input torque is constant (Table 1) - red line

\section{MODAL FLEXIBILITY METHOD}

According to [2], since the Adams/Flex software has been released, MSC Adams uses modal flexibility method for analysis with flexible bodies. Finite element mesh is generated for a flexible body and modal superposition is applied. Deformations of the finite element model's nodes are approximated in the way shown in equation (5).

$$
u=\sum_{i=1}^{M} \varphi_{i} q_{i}
$$

where: $\mathrm{u}$ - modal deformations, $\mathrm{M}$ - the number of mode shapes, $\varphi_{i}$ - mode shape $q_{i}$ - scale factors or amplitudes (modal coordinates). Modal deformations contour plot is shown in Figure 17 and 18.

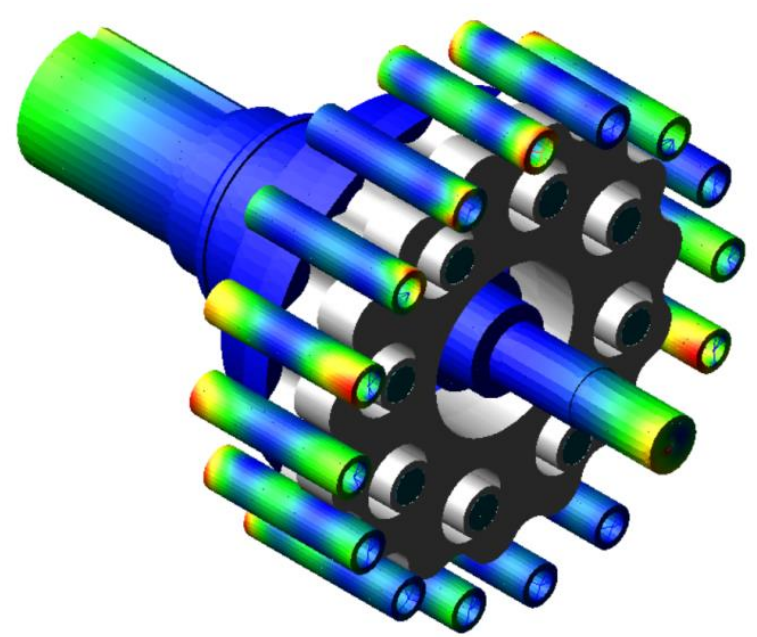

Fig. 17. Contour plot of the modal deformations in the model with flexible shafts and sleeves and two rigid cycloidal gears 


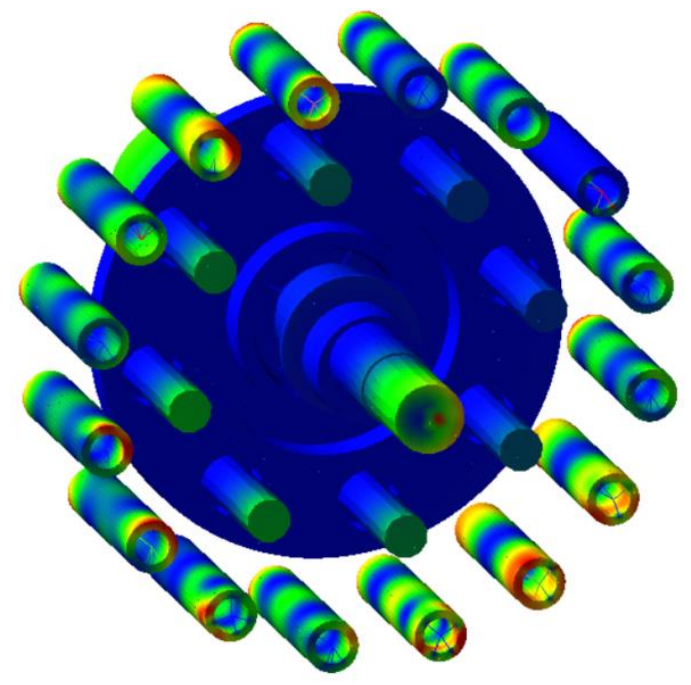

Fig. 18. Contour plot with hidden cycloidal gears. Modal deformations of four internal sleeves at the same time is shown

Contour graphs in Figure 17 and 18 show that deformation distribution on the sleeves is not even. The characteristic feature of a cycloidal gearbox shown in these Figures is that many sleeves work at the same time.

\section{CONCLUSIONS}

Kinematic analysis showed that the first model, with rigid bodies only, can be used for fast analysis. The number of peaks in Figure 4-7 corresponds to the number of revolutions of the input shaft. In position and velocity charts, first and second order oscillations are shown. The second order oscillations have higher frequency than the first order ones.

Forces acting on the external sleeves (Table 3) were calculated with static assumptions. Numerical simulation in MSC Adams takes into account inertia forces and the second model with flexible bodies takes into account modal deformations of the external sleeves. Forces calculated from static equilibrium (Equation 1 and 2) are 3 times lower than forces determined in MSC Adams.

Fluctuations of the input torque doesn't significantly influence the output torque. The responses (Figure 16) on the constant input torque and on the input torque with the fluctuation are of the same order.

In the part of the article, related to the calculation of the two stage cycloidal gear reducer, the MSC Software national scientific software license has been used, which is operated by the TASK Computer Centre. License has been funded by a computational grant obtained by Kazimierz Pulaski University of Technology and Humanities in Radom, Poland.

\section{BIBLIOGRAFIA}

1. M. Chmurawa, Cycloidal gears with tooth modification (in Polish, Obiegowe przekładnie cykloidalne z modyfikacją zazębienia). Silesian Technical University, Zeszyty naukowe, Nr 1547, 2002

2. MSC Software, "Using Adams/Flex" https://simcompanion.mscsoftware.com/infocenter/, pp. 129134, 2014

3. M. Wikło, K. Olejarczyk, K. Kołodziejczyk, K. Król, I. Komorska, Experimental vibration test of the cycloidal gearbox with different working conditions, Vibroengineering PROCEDIA. 13. 10.21595/vp.2017.19073., 2017

4. K. Olejarczyk, M. Wikło, K. Król, K. Kołodziejczyk, EXPERIMENTAL DETERMINATION OF THE FREQUENCY OF VIBRATION TEST BEACH FOR REDUCE. Technika Transportu Szynowego. 12., 2016

5. K. Olejarczyk, M. Wikło, K. Król, K. Kołodziejczyk, R. Nowak. EXPERIMENTAL IMPACT STUDIES OF THE APPLICATION MINERAL OIL AND SYNTHETIC OIL ON THE EFFICIENCY OF THE SINGLE-GEAR CYCLOIDAL. Tribologia. 1/2017. 067-073., 2017

\section{Kinematics and dynamics of the two stage cycloidal gearbox}

This article presents results of the numerical analysis of cycloidal gearbox, which were obtained in MSC Adams engineering software. Multibody geometry for dynamical analysis was designed in Autodesk Inventor Professional 2017 and imported in MSC Adams. The results of analysis are forces acting on the internal and external sleeves, position, velocity and acceleration of the selected points on the cycloidal gearbox's moving components. Indirect result is time course of the torque at output shaft which was calculated on the basis of forces acting on the internal sleeves, which are parts of the equilibrium mechanism and displacements of these sleeves. Knowledge about cycloidal gearbox's loading conditions is important in its design process. Main advantage of a cycloidal gearbox is distribution of the forces on multiple external sleeves, while in majority of other gears only one tooth is in contact at a time.

Autorzy:

dr inż. Roman Król - Uniwersytet TechnologicznoHumanistyczny im. Kazimierza Pułaskiego w Radomiu, Wydział Mechaniczny, Zakład Mechaniki, e-mail: roman.krol@hotmail.com

JEL: L97 DOI: 10.24136/atest.2018.125

Data zgłoszenia: 2018.05.23 Data akceptacji: 2018.06.15 